\title{
Optimization of an active phase composition in the low-temperature nitric oxide reduction catalyst
}

\author{
Marek Kułażyński, Krystyna Bratek, Jerzy Walendziewski \\ Wroctaw University of Technology, Faculty of Chemistry, Department of Fuels Chemistry and Technology, \\ ul. Gdańska 7/9, 50-344 Wroctaw, Poland, e-mail: marek.kulazynski@pwr.wroc.pl
}

\begin{abstract}
In the first research studies series a selection of the quantitative composition of catalyst active phase composition (iron, copper and manganese) deposited on mineral-carbon support was carried out. It was found on the basis of the selection studies series that the best results were attained when copper and manganese were used as catalyst components. The quantitative composition of the denitrogention catalyst was estimated using a statistical method of experiment planning and metals content changed in the range $0.5-1.5 \mathrm{wt} \%$ for both metals. Catalyst activity in nitric oxide reduction by ammonia was determined in the dependence on an active phase composition in the temperature range $100-200^{\circ} \mathrm{C}$, at GHSV (Gas Hour Space Velocity) 6000 and $10000 \mathrm{Nm}^{3} / \mathrm{m}^{3} \mathrm{~h}$, NO concentration $400 \mathrm{ppm}, \mathrm{NH}_{3} / \mathrm{NO}$ ratio 1:1. A graphic presentation of the obtained results was made using the UNIPLOT program. The highest activity in nitric oxide reduction by ammonia presented copper - manganese catalysts prepared by the impregnation of mineral-carbon support with active metals salts solutions and calcination after each metal impregnation with copper (up to $1.5 \mathrm{wt} \%$ ) and manganese (up to $1.5 \mathrm{wt} \%$ ).
\end{abstract}

Keywords: $\mathrm{NO}_{x}, \mathrm{SCR}$, catalyst, optimization, mineral-carbon carrier.

Presented at VII Conference Wasteless Technologies and Waste Management in Chemical Industry and Agriculture, Międzyzdroje, 12 - 15 June, 2007.

\section{INTRODUCTION}

The selective catalytic reduction (SCR) of nitrogen oxides using ammonia is a proven and used for a long time effective process of their eliminating from waste gases. The catalysts prepared by vanadium oxide deposition on titanium dioxide and lately on active carbons are applied in this process. Nitric oxides are reduced by ammonia and nitrogen and water are the reaction products ${ }^{1}$.

The efficiency of converting nitrogen oxides into neutral constituents of the atmosphere depends on the process temperature, their concentration and the presence

of oxygen in the waste gas, as well as the ammonia/ nitrogen oxides molar ratio. The catalyst's type and shape, its activity, life period and waste gases GHSV largely influence its efficiency. The presence of other impurities in the waste gas, e.g. $\mathrm{SO}_{2}$, determines the operational conditions of the process. In the classic SCR technology process is conduced in the temperature range of the 623 $-723^{\circ} \mathrm{K}^{2}$.

At present the SCR process is well known and attains high technological efficiency. Ceramic, monolithic honeycomb shape supports impregnated with active phase catalysts are offered by worldwide companies (Hitachi, Zosen, Shell, Grace, Engelhardt) and found the largest application in nitrogen oxides reduction ${ }^{1}$. The following processes are commercially accessible:

- titania support $\left(\mathrm{TiO}_{2}\right)$ based catalysts, working temperature $270-400^{\circ} \mathrm{C}$;

- zeolite based catalyst $\left(300-430^{\circ} \mathrm{C}\right)$,

- iron oxide based catalysts $\left(380-430^{\circ} \mathrm{C}\right)$.

Worldwide energetic plants are exploiting mainly the high-temperature flue gases denitrogenation processes, with the titania based monolithic catalysts.

Transition metals oxides deposited on mineral supports $\left(\mathrm{TiO}_{2}, \mathrm{Al}_{2} \mathrm{O}_{3}, \mathrm{SiO}_{2}, \mathrm{ZrO}_{2}, \mathrm{ZSM}-5\right)$ are mainly applied in nitrogen oxides reduction processes, for instance vanadia deposited on supports: $\mathrm{V}_{2} \mathrm{O}_{5} / \mathrm{TiO}_{2}, \mathrm{~V}_{2} \mathrm{O}_{5} / \mathrm{WO}_{3} / \mathrm{TiO}_{2}$, $\mathrm{V}_{2} \mathrm{O}_{5} / \mathrm{Al}_{2} \mathrm{O}_{3}, \mathrm{~V}_{2} \mathrm{O}_{5} / \mathrm{TiO}_{2} / \mathrm{SiO}_{2}$. However, the largest commercial application was found mainly by the following monolithic catalysts $\mathrm{V}_{2} \mathrm{O}_{5} / \mathrm{Al}_{2} \mathrm{O}_{3}, \mathrm{~V}_{2} \mathrm{O}_{5} / \mathrm{WO}_{3} / \mathrm{TiO}_{2}, \mathrm{NiO} /$ $\mathrm{Cu}_{2} \mathrm{O} / \mathrm{Al}_{2} \mathrm{O}_{3}{ }^{3-6}$.

Active carbon based catalysts exploited in some energetic plants are offered in the grain form (extrudates or pellets), however they are characterized by a large pressure drop (waste gases flow resistance), a necessity of high level gas de-dusting and relatively low waste gas flows (catalyst loading). The honeycomb catalyst shape ensures the highest external geometric surface area in the volume unit. The main advantages of such a catalyst in comparison to the grain form are:

- smaller front area of this catalyst bed, resulting in lower gas flow resistance,

- tolerance of larger dust concentration in flue gases, the catalyst's channel blockade by dust deposition is much more lower,

- possibility of using a higher linear gas velocity, resulting in the lowering of external diffusion resistance in the catalyst beds,

- considerably lower catalyst attrition losses of catalytic material.

The honeycomb catalysts structure also ensures uniform flue gases flows and temperature distribution.

In this paper optimization of mineral carbon based SCR catalyst composition was carried out. It was found in earlier studies $^{7,8}$ that the application of active carbon and inorganic mineral binder mixture is a very promising idea for support manufacturing. The mineral binder presence in the, subjected to the honeycomb forming monolith, precursors considerably improves the rheological properties, makes the forming operation easier and improves the mechanical strengths of the final support. As a result of 
extensive technical studies the mineral-carbon monolithic support manufacturing method was worked out.

\section{EXPERIMENTAL}

Hard coal, the 34 type and the natural alumina-silicate (Jaroszów deposit) as well as the binding and forming supporting materials were used as raw materials for the monolithic support production.

The mineral - carbon supports have been manufactured as honeycomb monoliths of the $1000 \times 100 / 100 \mathrm{~mm} \mathrm{di}-$ mensions, the wall thickness of $1 \mathrm{~mm}$, and 196 longitudinal channels visible at the cross section area $(14 \times 14)$.

The first catalysts series was prepared by depositing the same active phase weight percent on the carbon mineral support samples. Catalysts were prepared using crushed ceramic - carbon monoliths (grain size $0.63-1 \mathrm{~mm}$ ) and the water solution of copper (II) nitrate, ferric (II) nitrate and manganese (II) nitrate as impregnation agents. All active phases were deposited by the dry impregnation method. After impregnation the obtained catalyst samples were dried at the temperature of $110^{\circ} \mathrm{C}$ (overnight) and calcined in oxygen free atmosphere at $360^{\circ} \mathrm{C}$ (for 3 hours).

The composition of the final catalysts was as follows:

CAT 1: $2.5 \mathrm{wt} \% \mathrm{Cu}+2.5 \mathrm{wt} \% \mathrm{Mn}$ (calcination after each metal impregnation),

CAT 2: 2.5 wt $\% \mathrm{Cu}+2.5 \mathrm{wt} \% \mathrm{Mn}$ (one calcination after the impregnation with two metals),

CAT 3: $2.5 \mathrm{wt} \% \mathrm{Fe}$,

CAT 4: $2.5 \mathrm{wt} \% \mathrm{Cu}$,

CAT 5: $2.5 \mathrm{wt} \% \mathrm{Mn}$.

On the basis of the results of the first series activity tests the copper and manganese containing catalysts were selected for further studies. The active metals were deposited by dry impregnation with the water solution of active metals salts and the calcination after each metal impregnation.

Estimation of the influence of the catalyst's composition on its activity was performed by the mathematical method of the experiment result analysis. The second level regression equation of the general form:

$\mathrm{Y}=\mathrm{a}_{0}+\sum \mathrm{a}_{\mathrm{i}} \mathrm{x}_{\mathrm{i}}+\sum \mathrm{a}_{\mathrm{ij}} \mathrm{x}_{\mathrm{i}} \mathrm{x}_{\mathrm{j}}+\sum \mathrm{a}_{\mathrm{ii}} \mathrm{x}_{\mathrm{i}}^{2}$

was used, where $Y$ catalyst activity, $a_{0}, a_{1} \ldots a_{12} \ldots a_{11}-$ model coefficients, $x_{i}, x_{j}-$ active metals content. Standardization of the variables ( $x_{1}$ - copper, and $x_{2}-$ manganese $)$ allowed changing the active metals content in the range $0.5-1.5$ wt $\%$, at three levels: $0.5,1.0$ and $1.5 \mathrm{wt} \%$.

The results of the catalyst activity estimation were presented in the form of a graphic presentation using the Uniplot programme, which makes it possible to plot the three dimensions dependence of NO conversion on the active phase composition at the established GHSV and the process temperature.

The research studies were carried out in a laboratory flow apparatus, using the model gas of a determined chemical composition (NO content) similar to flue gases from the power plant. The apparatus (Figure 1) consisted of a model gas feeding system and the dosage system, the catalytic reactor and the analyser for determining the content of nitric oxide in the gas. $10 \mathrm{~cm}^{3}$ of the tested catalyst (0.63 - $1.0 \mathrm{~mm}$ fraction) was loaded into the reactor. Activity tests were carried out using model gas supplying $\mathrm{GHSV}=6000 \mathrm{~h}^{-1} ; 10000 \mathrm{~h}^{-1}$ in the temperature range
Table 1. Chemical composition of the prepared catalysts (the second series)

\begin{tabular}{|c|c|c|}
\hline Catalyst & Copper content, wt \% & $\begin{array}{c}\text { Manganese } \\
\text { content, wt \% }\end{array}$ \\
\hline $\mathrm{K} 1$ & 0.5 & 1.5 \\
\hline $\mathrm{K} 2$ & 1 & 1.5 \\
\hline $\mathrm{K} 3$ & 1.5 & 1.5 \\
\hline $\mathrm{K} 4$ & 0.5 & 1 \\
\hline $\mathrm{K} 5$ & 1 & 1 \\
\hline $\mathrm{K} 6$ & 1.5 & 1 \\
\hline $\mathrm{K} 7$ & 0.5 & 0.5 \\
\hline $\mathrm{K} 8$ & 1 & 0.5 \\
\hline $\mathrm{K} 9$ & 1.5 & 0.5 \\
\hline
\end{tabular}

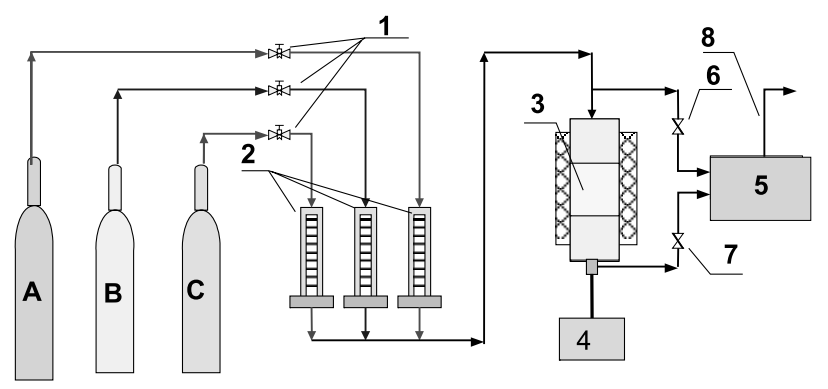

Figure 1. The apparatus for the SCR catalyst testing: A ammonia in nitrogen containing cylinder, $\mathrm{B}-\mathrm{ni}$ trogen and air mixture containing cylinder, $\mathrm{C}$ nitric oxide in nitrogen containing cylinder, 1 reducing valves, 2 - rotameters, 3 - reactor with the catalyst, 4 - temperature indicator, 5 - MSI 2500 Analyzer, 6 - control valve (before catalyst), 7 - control valve, 8 - gas outlet

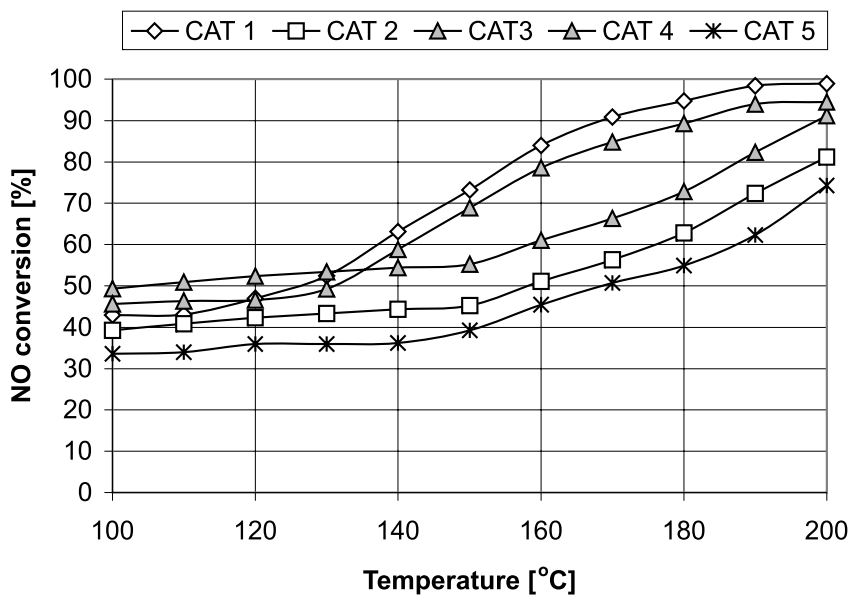

Figure 2. The influence of temperature on nitric oxide reduction over the first catalyst series (GHSV $=6000 \mathrm{~h}^{-1}$, the catalyst composition is given in the experimental section)

$100-200^{\circ} \mathrm{C}$. The oxygen content in the model gas was $6 \%$, NO content $400 \mathrm{ppm}$, and ratio $\mathrm{NH}_{3} / \mathrm{NO}=1: 1$. The influence of the copper and manganese content ( 0.5 up to $1.5 \mathrm{wt} . \%$ ) on the catalyst surface, the temperature of the SCR reaction and the gas flow space velocity, were determined.

\section{DISCUSSION OF THE OBTAINED RESULTS}

The results of the selective catalytic reduction of nitric oxide by ammonia with using prepared mono- $(\mathrm{Cu}, \mathrm{Fe}$, $\mathrm{Mn}$ ) and copper - manganese catalysts are graphically presented in Fig. 2. The highest activity in the SCR reac- 


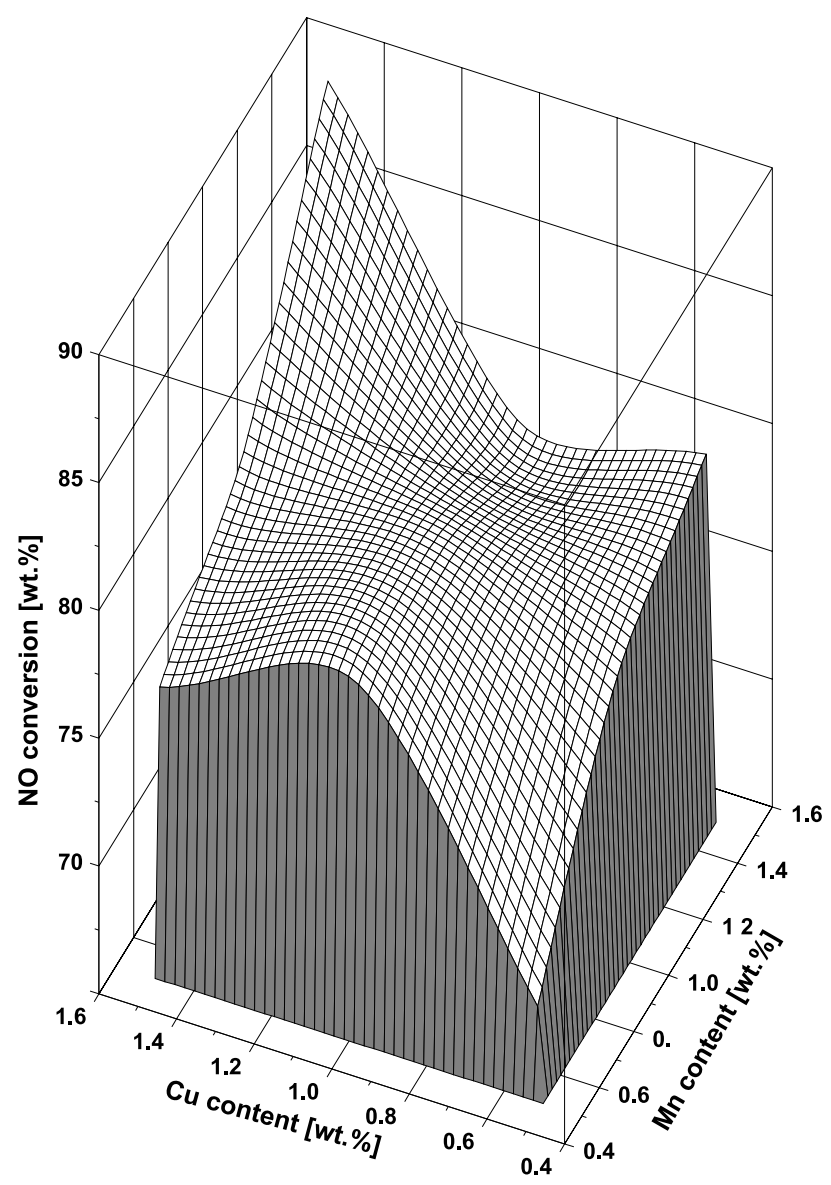

Figure 3. Dependence of the NO conversion on the $\mathrm{Cu}$ and $\mathrm{Mn}$ content in the catalyst $\left(160^{\circ} \mathrm{C}, \mathrm{GHSV}=6000 \mathrm{~h}^{-1}\right)$

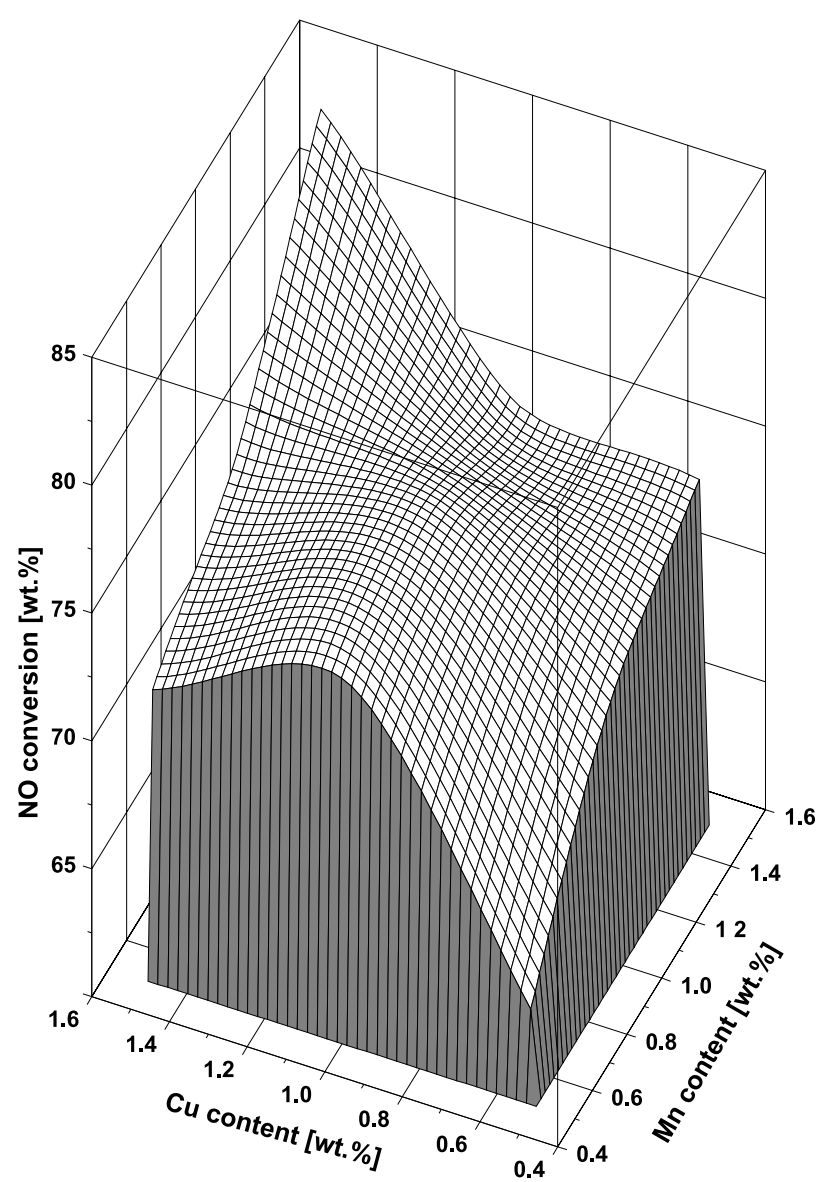

Figure 4. Dependence of the NO conversion on the $\mathrm{Cu}$ and $\mathrm{Mn}$ content in the catalyst $\left(160^{\circ} \mathrm{C}, \mathrm{GHSV}=10000 \mathrm{~h}^{-1}\right)$

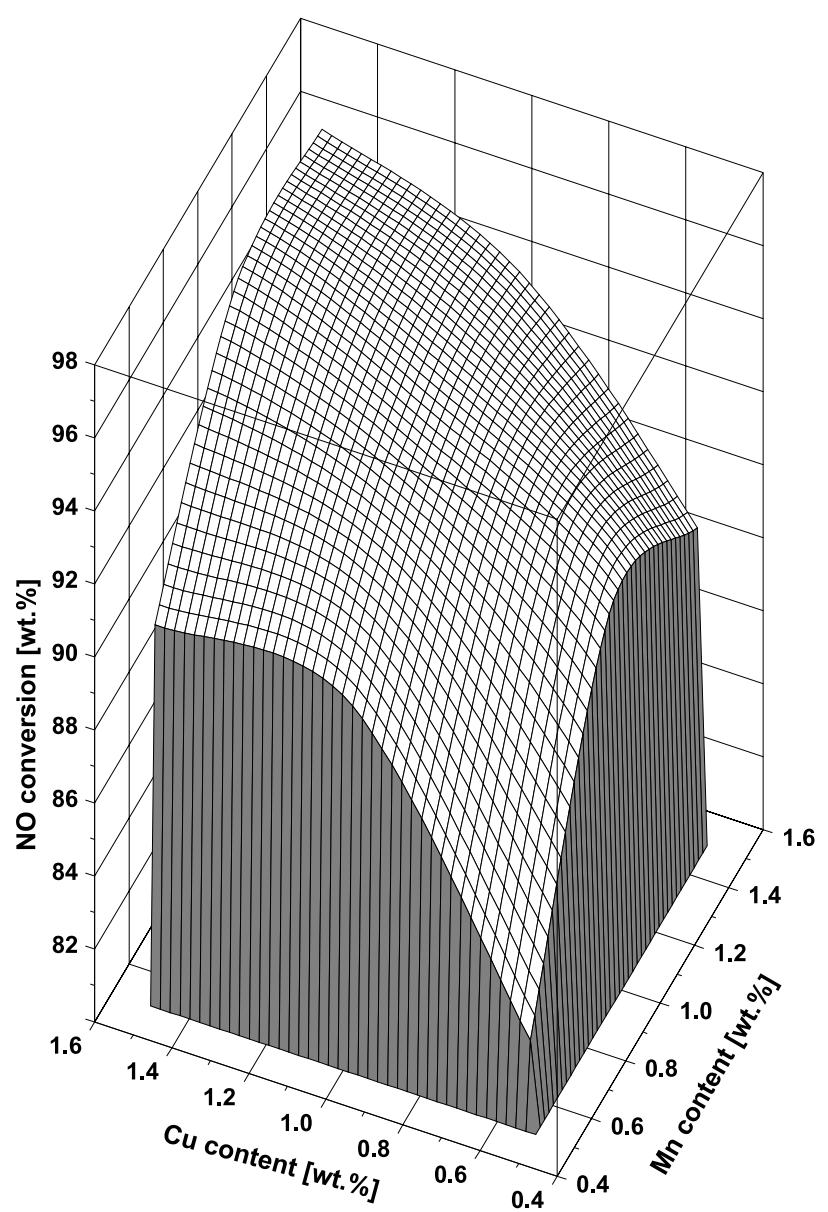

Figure 5. Dependence of the NO conversion on the $\mathrm{Cu}$ and $\mathrm{Mn}$ content in the catalyst $\left(200^{\circ} \mathrm{C}\right.$, GHSV $\left.=6000 \mathrm{~h}^{-1}\right)$

tion was attained by the $\mathrm{Cu}-\mathrm{Mn}$ catalyst, prepared by a two-step impregnation with calcination after each metal oxide depositing. Nitric oxide conversion at the temperature ca $160^{\circ} \mathrm{C}$ was higher than $80 \%$. Therefore, the $\mathrm{Cu}-$ Mn catalyst was subjected to further studies in order to optimize the active phase quantitative composition.

In order to optimize the catalyst composition in the next step of the studies, nine catalysts with various active metals content have been prepared according to the statistical method of experiment planning. The metals' content was changed in the range $0.5-1.5 \mathrm{wt} \%$ and the catalyst compositions are presented in Table 1 . The selected results of the realized activity studies are presented in Figs. 3, 5 $\left(\mathrm{GHSV}=6000 \mathrm{~h}^{-}\right.$and 4, $6\left(\mathrm{GHSV}=10000 \mathrm{~h}^{-1}\right)$.

The analysis of the graphical presentations suggests that the obtained nitric oxide conversions are decreasing with the increase of the catalyst loading (GHSV). It is the result of diminishing the contact time i.e. diminishing the residence time of the reaction mixture in the catalyst bed. On the other, hand increasing the catalyst loading (GHSV) can strongly influence the external diffusion limitation. Therefore, the application of higher GHSV (e.g. 10000 $\mathrm{h}^{-1}$ and higher), should give provide an objective catalyst activity comparison.

At the steady state tests parameters $\left(\mathrm{NH}_{3} / \mathrm{NO}=1\right.$, $\left.\mathrm{GHSV}=6000 \mathrm{~h}^{-1}, \mathrm{CNO}=400 \mathrm{ppm}\right)$ the highest nitric oxide reduction by ammonia was obtained using the K3 catalyst $(1.5 \mathrm{wt} \% \mathrm{Cu}$ and $1.5 \mathrm{wt} \% \mathrm{Mn})$. In the presence of this catalyst in the temperature range of $160-200^{\circ} \mathrm{C}$, 


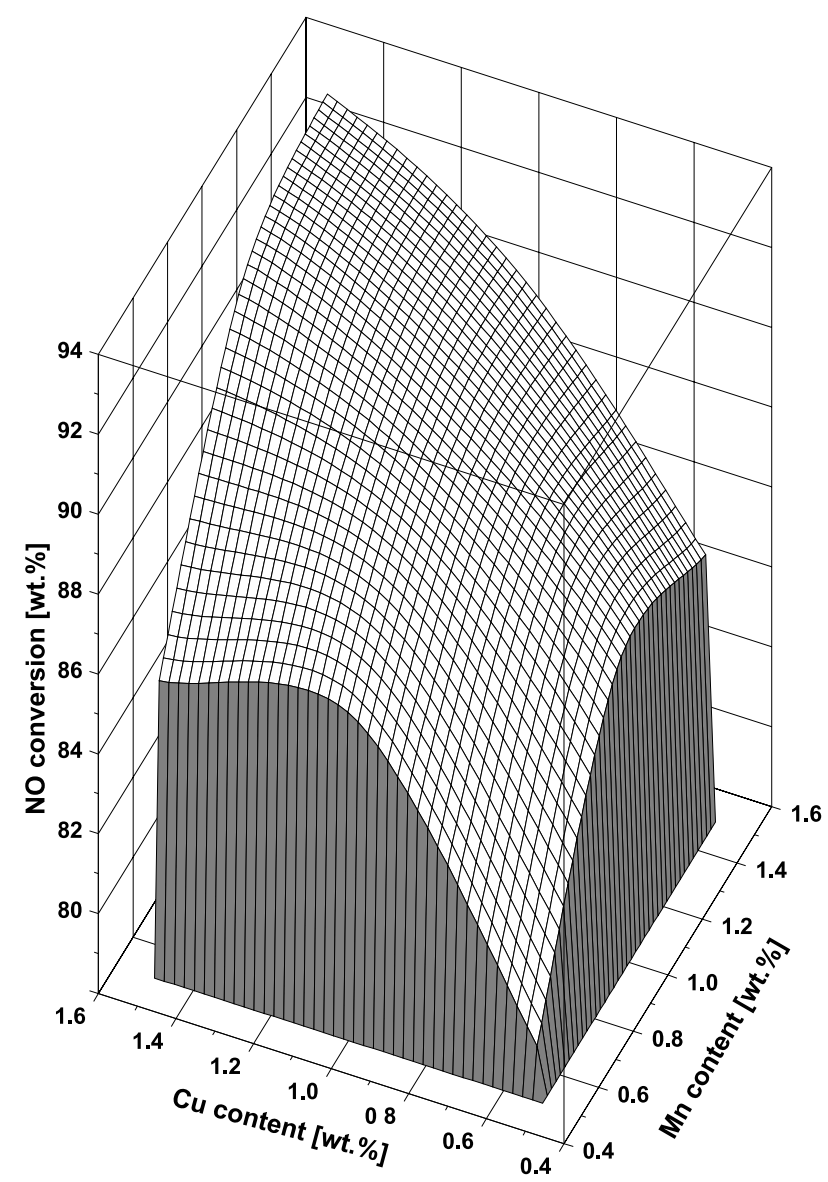

Figure 6. Dependence of the $\mathrm{NO}$ conversion on the $\mathrm{Cu}$ and $\mathrm{Mn}$ content in the catalyst $\left(200^{\circ} \mathrm{C}, \mathrm{GHSV}=10000 \mathrm{~h}^{-1}\right)$

quite high conversion levels, higher than $80 \%$ were obtained.

Others catalysts of this series, demonstrating the lower active metals contents presented a distinctly lower (by 10 $-20 \%$ ) activity in comparison to the $\mathrm{K} 3$ catalyst. It means that the increase in the active metal content in the $\mathrm{Cu}-\mathrm{Mn} /$ mineral-carbon catalyst (over $1.5 \mathrm{wt} \%$ ) can further increase the activity and the conversion level of nitric oxide up to ca $90 \%$ and higher.

The data presented in Fig. 7 shows that the highest conversion increase occurs in the temperature range of $140-160^{\circ} \mathrm{C}$. It means that temperature in the SCR reaction process should be higher than $160^{\circ} \mathrm{C}$, preferably 180 $-200^{\circ} \mathrm{C}$. Because of the high carbon content (coal and mineral clay, weight ratio $4: 1$ ), this type of a mineralcarbon based catalyst should not be exploited at temperatures higher than $200^{\circ} \mathrm{C}$. One can also see that the catalyst's loading moderately influences nitric oxide conversion, the differences in conversion levels attained at GHSV 6000 and $10000 \mathrm{~h}^{-1}$ were $10-15 \%$.

In order to compare the activity of grain and honeycomb monolithic catalysts, additional research studies were realised. Preparation of the K3 catalyst was repeated, however the monolithic support, instead of grain support, was used. A dimension of the monolith support was as follows: 40x40x200 mm, the wall thickness $1 \mathrm{~mm}$ and 196 parallel channels. The activity of this catalyst was determined in the reactor system similar to the one presented in Fig. 1, however the reactor size enabled the loading of the whole monolithic support. The results presented in Fig. 8 clearly show that application of monolithic catalyst

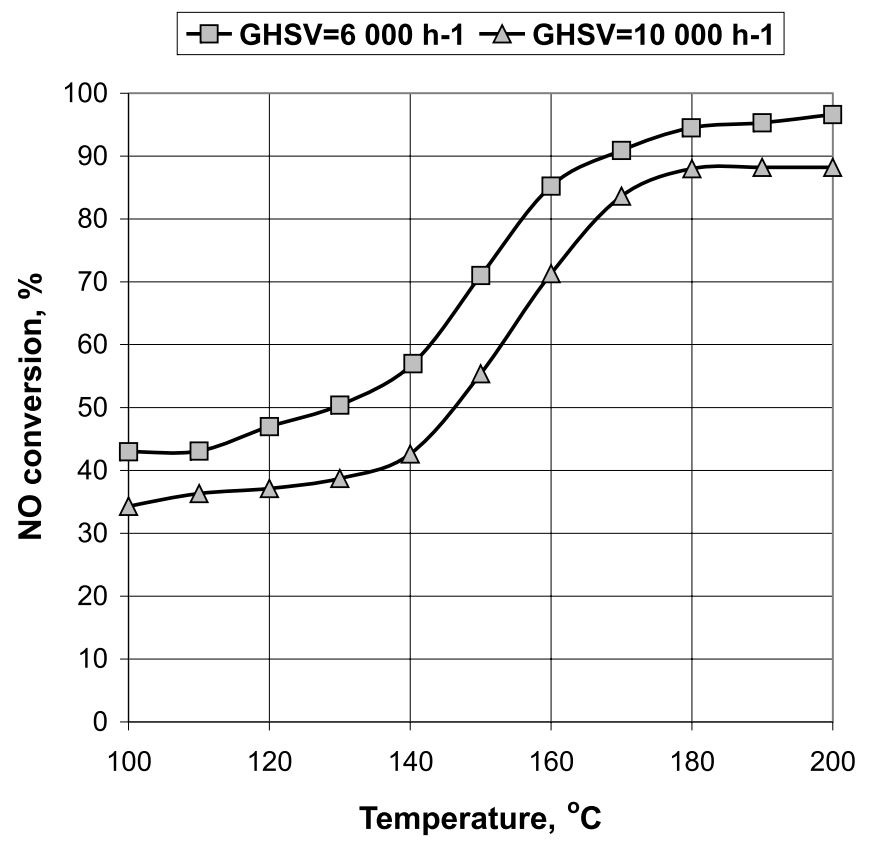

Figure 7. The influence of the catalyst loading (GHSV) and the temperature on the nitric oxide reduction over the best (1.5 wt \% Mn and $1.5 \mathrm{wt} . \% \mathrm{Cu} /$ mineral-carbon) catalyst

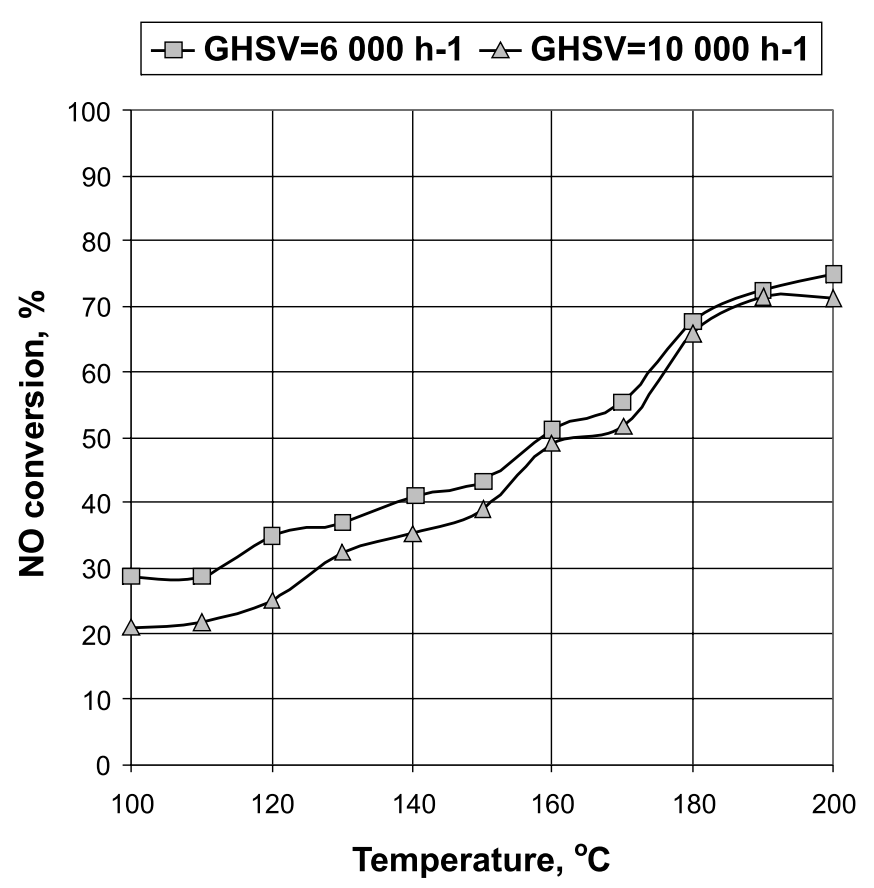

Figure 8. The influence of the catalyst loading (GHSV) and the temperature on the nitric oxide reduction over the monolithic (1,5 wt \% $\mathrm{Mn}$ and $1,5 \mathrm{wt} \% \mathrm{Cu} /$ mineralcarbon) catalyst

generates a considerably lower conversion than the grain form catalyst (about 30\%) but one can observe a smaller influence of GHSV on the conversion level. Presumably it is the result of diminishing the external diffusion resistance in the case of applying higher GHSV.

\section{CONCLUSIONS}

1. The realized studies presented the usability of mineral carbon monoliths for the manufacturing of low temperature SCR catalysts (at the temperature lower than $200^{\circ} \mathrm{C}$ )

2 . The active phase composed of copper and manganese could be successfully applied in the mineral carbon based 
SCR catalysts. The increase in the active metals content increases the catalyst activity.

3. The monolithic $\mathrm{Cu}-\mathrm{Mn}$ SCR catalyst enables obtaining a lower nitric oxide reduction level in comparison with the grainy $\mathrm{Cu}-\mathrm{Mn}$ catalyst. A small difference in the conversion level at both GHSV (6 000 and $\left.10000 \mathrm{~h}^{-1}\right)$ suggests the presence of the external diffusion limitation in the monolithic catalyst bed at lower GHSV $\left(6000 \mathrm{~h}^{-1}\right)$ and decreased or eliminated at higher GHSV $\left(10000 \mathrm{~h}^{-1}\right)$.

\section{ACKNOWLEDGEMENTS}

The financial support of Polish Ministry of Science and Information Society Technologies under 3 T09B 03627 project is gratefully acknowledged.

\section{LITERATURE CITED}

(1) Fumito N., Ikubisa H.: The state of the art of NOx control, Catal. Today, 1996, 29, 109.

(2) Olivares J., Kułażyński M., Salwador L., Walendziewski J., Trawczyński J.: Laboratory and pilot plant performance of novel carbon monolithic catalysts development for selective flue gas d-NOxing at low temperature. Proc. Conf. Catalysis and Adsorption in Fuel Processing and Environmental Protection, Oficyna Wydawnicza Politechniki Wrocławskiej, Wrocław, 2002, 169.

(3) Van der Grift C. J. G., Woldbuis A. F, Maaskant O. L.: The Shell DENOX-system for low temperature NOx removal, Catal. Today, 1996, 27, 23.

(4) Wojciechowska M., Łomnicki S., Derewiński M., Haber J., Kryściak J.: Catalytic reduction of NO by carbon monoxide over supported copper oxide, Polish J. Environ. Studies, 1997, 6, 75.

(5) Castillo S., Moran-Pineda M., MolinaV., Gomez R., Lopez T.: Catalytic reduction of nitric oxide on $\mathrm{Pt}$ and $\mathrm{Rh}$ catalysts supported on alumina and titania synthesized by the sol-gel method, Appl. Catal. B, 1998, 15, 203.

(6) Bosch H., Janssen F.: Catalytic reduction of nitric oxides-a review on the fundamentals and technology, Catal. Today, 1997, 2, 370.

(7) Kułażyński M., Walendziewski J., Bratek K.: Synthesis of mineral-carbon monolithic catalyst supports, Conference on Porous Ceramic Materials. PCM 2005. Brugge, Flemish Institute for Technological Research (Vito), Belgium, 20 21 October 2005.

(8) Kułażyński M., Walendziewski J.: DENOX activity of mineral carbon catalysts supported on monolithic material, Pol. J. Environ. Stud., 2006, 15, 6A, 95. 